\title{
Bisphosphonates in Breast Cancer Patients with Bone Metastases
}

\author{
Ingo J. Diel \\ Schwerpunktpraxis für Gynäkologische Onkologie, Mannheim, Germany
}

\section{Keywords}

Bisphosphonates - Clodronate - Pamidronate - Ibandronate . Zoledronic acid . Breast cancer, Metastatic bone disease . Osteonecrosis of the jaw

\section{Summary}

Morbidity and mortality in breast cancer patients are mainly caused by organ failure as a result of distant metastasis. The main target of metastatic disease is the skeleton (next to lungs and liver). Osseous metastases are diagnosed in $75-80 \%$ of all women who die due to breast cancer; and the skeleton is the primary metastatic target organ in more than half of these cases. In Germany, the incidence of breast cancer patients with newly diagnosed bone metastases is approximately $11-12,000$ cases. Prevalence might amount to 40,000 cases of women with breast cancer and osseous metastases at a median survival time of 3-4 years. The treatment goal at this stage of the disease comprises improvement of quality of life, and reduction of bone pain and typical complications like fractures and hypercalcemia. By consistent use of bisphosphonates these goals can be accomplished. Bisphosphonates improve bone pain significantly and reduce the number of skeletal-related events in women with bone metastases. Bisphosphonates can be administered intravenously or orally, and are well tolerated. Nevertheless, there are side effects and complications including acute phase reaction, nephrotoxicity, osteonecrosis of the jaw, and gastrointestinal disturbances.

\section{History and Chemistry of Bisphosphonates}

Bone metastases can be treated locally with radiation therapy, or surgically. Systemic options include chemotherapy, antibody therapy, and endocrine treatment. Classical pain treatment and treatment with radioisotopes can also be used in the fight against bone metastases, as well as anti-osteolytic treat-

\author{
Schlüsselwörter \\ Bisphosphonate - Clodronat - Pamidronat - Ibandronat . \\ Zoledronat · Brustkrebs, Knochenmetastasen . \\ Kieferosteonekrosen
}

\section{Zusammenfassung}

Hauptursache der Morbidität und Mortalität beim Mammakarzinom ist die distante Metastasierung und das daraus resultierende Organversagen. Hauptlokalisation der Metastasierung ist das Skelett (neben Lunge und Leber). Ossäre Metastasen findet man bei $75-80 \%$ aller Frauen, die am Brustkrebs versterben, und in mehr als der Hälfte dieser Fälle ist das Skelett das primäre metastatische Zielorgan. In Deutschland liegt die Zahl der Patientinnen, die jährlich neu an Knochenmetastasen erkranken, bei 11-12 000. Bei einer durchschnittlichen Überlebenszeit von 3-4 Jahren dürfte die Prävalenz von Frauen mit Brustkrebs und ossären Metastasen bei 40000 Fällen liegen. Therapieziele in diesem Stadium der Erkrankung sind die Verbesserung der Lebensqualität, und die Vermeidung des Knochenschmerzes und typischer Komplikationen wie Frakturen und Hyperkalzämie. Durch den konsequenten Einsatz von Bisphosphonaten können diese Ziele erreicht werden. Bisphosphonate verbessern signifikant den Knochenschmerz und reduzieren die Zahl skelettaler Ereignisse bei Frauen mit Knochenmetastasen. Bisphosphonate können intravenös oder oral verabreicht werden und sind gut verträglich. Trotzdem gibt es Nebenwirkungen und Komplikationen: dazu gehören die Akute-Phase-Reaktion, die Nephrotoxizität, Kieferosteonekrosen und gastrointestinale Störungen.

ment with bisphosphonates [1, 2]. Bisphosphonates are chemically related to pyrophosphate, and are a part of the polyphosphate family. Polyphosphates were developed in the 19th century for use as a tube descaler among others (water softener). The first bisphosphonate, which is still used therapeutically (etidronate), stems from this time period. Therapeutic efficacy in the fight against hypercalcemic conditions

\section{KARGER}

Fax +497614520714

Information@Karger.de

www.karger.com (c) 2010 S. Karger GmbH, Freiburg

Accessible online at:

www.karger.com/brc
Prof. Dr. med. Ingo J. Diel

Schwerpunktpraxis für Gynäkologische Onkologie Quadrat P 7, 16-18

68161 Mannheim, Germany

diel@spgo-mannheim.de 
was developed toward the end of the 1960s. Since this time, clinical development has advanced, and bisphosphonates are now used as treatment for bone metastases, osteoporosis, Paget's disease of the bone, and other illnesses that are accompanied by an increase in bone metabolism. In contrast to pyrophosphates that have a P-O-P bond and are relatively unstable, bisphosphonates have a carbon atom between the two phosphorus atoms (P-C-P). The free valences on the $\mathrm{C}$ atom enable a variety of molecules with side chains characteristic of the various bisphosphonates. Clodronate is relatively simply constructed with two chlorine atoms attached to a carbon atom. The newer bisphosphonates, with somewhat complex side chains, exceed the binding capacity (to the bony matrix) of etidronate and clodronate, but they also have a different range of side effects [3].

\section{Mode of Action of Bisphosphonates}

Until a few years ago, the mechanism of action for bisphosphonates at the molecular level was unexplained. The antiosteolytic effect was seen - quite correctly - as a reduction in osteoclastic activity. Today, we know that this effect primarily forms the basis for the induction of apoptotic processes (fig. 1) [4]. The aminobisphosphonates (e.g. pamidronate, ibandronate, risedronate, alendronate, zoledronate) competitively inhibit geranylation and farnesylation in the mevalonate metabolism, which on the other hand is essential for cholesterol synthesis. In this way, the effect and function of GTPbinding proteins is suspended, which is interrupted by the intracellular signal transfer [5]. With the non-aminobisphosphonates (e.g. clodronate, tiludronate and etidronate), apoptosis (and necrosis) is achieved through intracellular accumulation of toxic metabolites of ATP [6]. Regrettably, this apoptotic effect can also be seen in cells of the intestinal mucosa and in renal tubular cells.

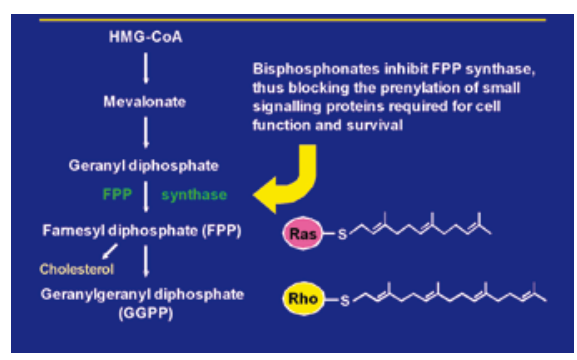

Fig. 1. Molecular mechanism of action of nitrogen-containing bisphosphonates.

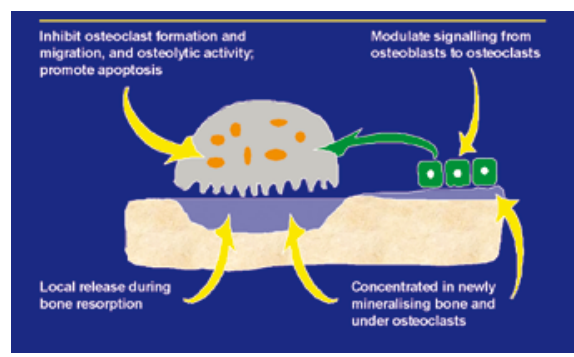

Fig. 2. Mechanisms of action of bisphosphonates

\section{Pharmacology of Bisphosphonates}

Bisphosphonates can be administered orally and parenterally. However, absorption through the intestinal mucosa is ineffective and dependent on food composition. For this reason, oral bisphosphonates must be taken on an empty stomach and calcium-rich meals, and drinks must be avoided for 30-60 min as otherwise chelates may form. All in all, the resorption rates are between 0.5 and $5 \%$. Initially, this is meaningless except that tablets in comparison to parenterally administered bisphophonates must be given in higher doses (similar to antibiotics). Bisphosphonates, regardless of the route of administration, are stored on the calcium apatite of the mineralized bone matrix (30-70\%) or remain unmetabolized and are excreted by the kidneys. In areas of increased bone turnover, uptake is particularly high (principle of skeletal scintigraphy with technetium bound to bisphosphonate). Osteoclasts take up bisphosphonates with microsequestration from the bone matrix. Bisphosphonates on the other hand induce in osteoclasts the above-described apoptotic processes (fig. 2) [3, 4].

\section{Clinical Efficacy of Bisphosphonates}

The therapeutic goal of using anti-osteolytic drugs is the reduction of skeletal-related events, including reduction of pathological fractures and hypocalcaemia, reduction of the need for surgery or radiation therapy, and especially reduction of bone pain. Due to their effectiveness in fighting these complications, bisphosphonates contribute considerably to improvement of quality of life and preservation of mobility of the patient. The osteoprotective effect also contains a significant effect on the occurrence of tumor therapy-induced osteoporosis, which makes the adjuvant use seem far more important. In other words, bisphosphonates have two effects: they protect the remaining skeleton from further destruction (osteoprotection), and by relieving pain they have an enormous influence on quality of life. For no other tumor entity is there as much data on bisphosphonate treatment as for breast cancer. Clodronate, pamidronate, ibandronate, and zoledronate are all approved in Germany and most countries in Europe.

\section{Treatment with Clodronate}

Clodronate is a first generation bisphosphonate and can be administered intravenously $(1,500 \mathrm{mg} /$ over $4 \mathrm{~h}$ every $3-4$ weeks) or orally $(1,600 \mathrm{mg} /$ day $)$. Intravenous administration is suitable for normalization of hypercalcemia and to reduce skeletal complications, but because of long infusion times and the large number of molecules it is not frequently used in contrast to oral medication. Unlike all others common bisphosphonates used in oncology, clodronate is a non-aminobisphosphonate and has another mode of action than an amino- 
bisphosphonate (see above). Clodronate is approved for the treatment of hypercalcemia and for osteolytic destruction by metastases of solid tumors (e.g. breast and prostate cancer) or hematological neoplasias (e.g. multiple myeloma). Therefore, clodronate - besides intravenous zoledronate - has a general labeling for the treatment of bone metastases of different origin [7]. Oral clodronate also decreases the rate of skeletal complications, but is not very effective against hypercalcemia or acute bone pain [7]. The scope of application lies primarily in preventing these complications (asymptomatic metastases) and in adjuvant treatment to avoid subsequent metastases. Side effects of oral clodronate are rare. Gastrointestinal disturbances, particularly diarrhea in up to $10 \%$ of cases, are typical. Osteonecrosis of the jaw (ONJ), nephrotoxicity, and acute phase reactions are unknown or extremely rare.

\section{Treatment of Bone Metastases with Pamidronate}

For many years, pamidronate has been standard treatment for carcinomas with bone metastasis. Because oral treatment has been shown to be too toxic, in Germany as in most countries only the intravenous formulation is used $(90 \mathrm{mg}$ over $2 \mathrm{~h}$ every 3-4 weeks). Intravenously administered bisphosphonates are $100 \%$ bioavailable and do not depend on individual intestinal resorption rates which in contrast may be affected by meal times and calcium-rich components of the diet. Pamidronate was the first aminobisphosphonate approved for treatment of hypercalcemia and osteolytic disease due to breast cancer and multiple myeloma. Pamidronate is more potent than clodronate, which is attributed to the strong affinity of the drug to hydroxylapatite on the bone surface. The broadest use of pamidronate was as interval therapy at a dose of $90 \mathrm{mg} / \mathrm{every} 4$ weeks. Pamidronate has the following clinically relevant side effects: acute phase reaction, nephrotoxity (rare), and ONJ.

\section{Advanced Clinical Information}

The reference study on the use of pamidronate/intravenously was published in December 1996 by Hortabagyi et al. [8]. In this multicentre, double blind, placebo-controlled study, patients with osteolytic destruction $(\mathrm{n}=382)$ were given either pamidronate as well as chemotherapy at a dose of $90 \mathrm{mg}$ intravenously every 4 weeks or placebo (for 1 year $=12$ cycles). In the pamidronate group, the appearance of extravertebral fractures was significantly reduced, as well as bone pain and the need for radiation therapy. Nevertheless, there was no reduction in vertebral fractures. A follow-up study with a significantly longer follow-up time confirmed the pamidronate effects $[9,10]$. Interestingly, the approval studies for pamidronate compared to the placebo group showed a life-prolonging effect in the subgroup of premenopausal patients (24.6 vs. 15.7 months). Similar observations were made with multiple myeloma [11].

\section{Treatment of Bone Metastases with Ibandronate}

Ibandronate is a highly potent third generation bisphosphonate that has been approved for intravenous administration since 2003 for treatment of bone metastases in breast cancer. Orally it has been available for treatment of breast cancer osteolysis since April 2004. Typical for the substance is its good tolerability and the low number of unexpected effects. Ibandronate is approved for the treatment of hypercalcemia and for the reduction of skeletal complications due to bone metastases in breast cancer patients [12]. Acute phase reaction is a typical side effect $(<20 \%)$. ONJ is rare and nephrotoxicity very rare for intravenous ibandronate. With oral ibandronate, gastrointestinal side effects are less than $10 \%$.

\section{Advanced Clinical Information}

The studies on parenteral use were conducted using 2 and $6 \mathrm{mg}$ intravenous ibandronate versus placebo in 462 patients with breast cancer with skeletal metastases over 2 years [13]. While $6 \mathrm{mg}$ of ibandronate compared to placebo significantly reduced skeletal complications, this was not evident with $2 \mathrm{mg}$. With $6 \mathrm{mg}$, there was a significant reduction in vertebral but not in extravertebral fractures. On the other hand, the best effectiveness can be verified by the avoidance of radiation therapy. Furthermore, the $6 \mathrm{mg}$ dose led to a significant lengthening of the time period until the first skeletal complications appeared and to a lasting reduction in bone pain over 24 months (fig. 3). The study showed excellent results in improvement of quality of life for the affected patients in all areas measured (based on the EORTC-QLQ-C30 questionnaire) and in reduction in the need for pain medication (fig. 4) [14]. Three large comparative studies were performed for approval of oral ibandronate. In all 3 studies, $50 \mathrm{mg}$ vs. $20 \mathrm{mg}$ vs. placebo were respectively tested. In total, 999 patients with breast cancer with bone metastasis were included $[15,16]$. The results of the studies were roughly comparable.

Fig. 3. Long-term bone pain relief (up to 2 years) with intravenous ibandronate.

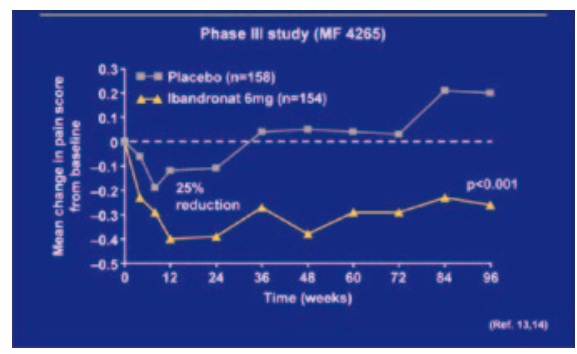

Fig. 4. Effect of ibandronate on quality of life.

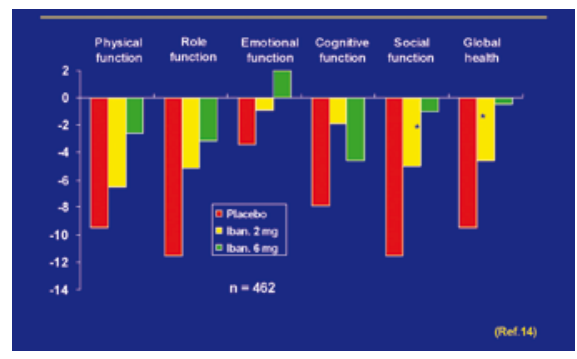


With the (approved) dose of $50 \mathrm{mg}$, a significant reduction in bone pain and in all skeletal events was achieved [17].

\section{Treatment of Bone Metastases with Zoledronate}

Zoledronate is one of the most potent bisphosphonates used in oncology, and in the phase III study of breast cancer and multiple myeloma it was for ethical reasons no longer tested against placebo, but against $90 \mathrm{mg}$ intravenous pamidronate. Zoledronate is the bisphosphonate with the widest spectrum of approval and can be used for the reduction of skeletal complications due to bone destruction of any tumor entity or multiple myeloma, and the treatment of hypercalcemia. Typical complications for zoledronic acid are acute phase reactions (in approximately 30\%), ONJ, and renal deterioration (measurement and calculation of creatinine clearance before application is mandatory!).

\section{Advanced Clinical Information}

In the treatment of hypercalcemia it was shown that zoledronate had a $10 \%$ higher response rate, and the time until hypercalcemia recurred was increased [18]. No other drug was tested before approval for treatment of metastases on such a large number of patients with breast cancer $(n=1,130)$. Zoledronate was administered in an equivalence study against $90 \mathrm{mg}$ pamidronate at a dose of $4 \mathrm{mg}$ and $8 \mathrm{mg}$ in patients with skeletal metastases over 12 months [19]. Results of the comparative study showed in the short-term no differences in efficacy between pamidronate and zoledronate. Both drugs demonstrated significant pain reduction. Because particularly the $8 \mathrm{mg}$ dose in some patients led to increases in serum creatinine, for the rest of the study the $8 \mathrm{mg}$ group was switched to $4 \mathrm{mg}$ and infusion time was increased to $15 \mathrm{~min}$. Renal toxicity from $4 \mathrm{mg}$ given over $15 \mathrm{~min}$ was in the final analysis in the same range as $90 \mathrm{mg}$ of pamidronate. In a longterm analysis of the approval study over 25 months in patients with breast cancer, a reduction of $20 \%$ in skeletal complications with $4 \mathrm{mg}$ of zoledronate compared to $90 \mathrm{mg}$ of pamidronate was proven (fig. 5) [20, 21]. Similarly, as with other bisphosphonates, this effect was achieved primarily by reducing necessary radiation treatment. This is a clear indication that the more potent drug (in comparison to pamidronate) in acute events is more effective, such as for bone pain and hypercalcemia. In the prevention of pathological fractures, this does not appear to be the case. These results were underscored by the results of an individual placebo-controlled study with zoledronate (Japan) that was published in May 2005 [22]. In this study, 114 patients with breast cancer with skeletal metastases were treated with $4 \mathrm{mg}$ of zoledronate every 4 weeks for a year, another 114 women received placebo infusions. There was a significant reduction in all evaluated skeletal complications with zoledronate. Impressive and longterm pain reduction was shown with $4 \mathrm{mg}$ of zoledronate,
Fig. 5. Effect of zoledronic acid on skeletal-related events (SREs) from breast cancer.

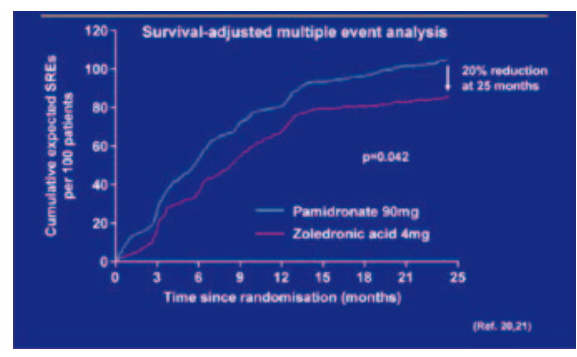

Fig. 6. Breast cancer: reduction of all types of skeletal events with zoledronate.

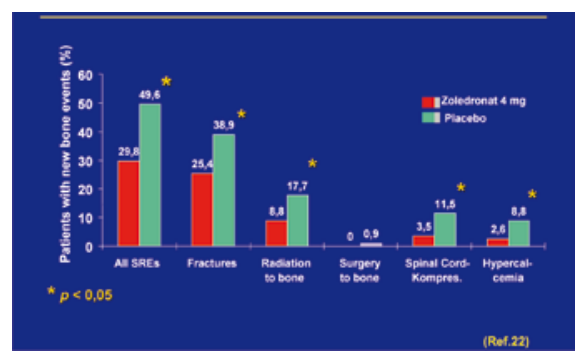

whereas the pain intensity in the placebo group significantly increased over time $(p<0.05)$ (fig. 6).

\section{Side Effects of Bisphosphonates}

If you want to understand the side effects of bisphosphonates, first you must be familiar with the mechanism of action of the drug class [4-6]. And this is also relevant for most side effects. As described above, bisphosphonates induce apoptotic processes in osteoclasts. But this effect is not only visible in osteoclasts and macrophages, but also in the corresponding accumulation in the intestinal mucosa and in the kidney tubules. With bisphosphonates, a distinction is made between infrequent and frequent adverse effects. Clinical oncologists should at least be familiar with those encountered most frequently: acute phase reaction, gastrointestinal disturbances, nephrotoxic complications, and recently ONJ.

\section{Acute Phase Reaction and Gastrointestinal Side Effects}

A large number of flu-like symptoms and findings are classified by the term acute phase reaction: including subfebrile temperatures, leukocytosis, abnormal fatigue, and muscle and bone pain [23]. These responses are seen exclusively in intravenously administered aminobisphosphonates (zoledronate, ibandronate, pamidronate) and typically appear after the first infusion at a frequency of up to $30 \%$. This type of side effect is not life-threatening, but is often perceived by the patient as very stressful and in rare cases leads to interruption of parenteral treatment. Symptoms as a rule regress at the latest after $48 \mathrm{~h}$ and respond well to non-steroidal antirheumatic agents and antipyretic measures. Bisphosphonate-induced side effects in the gastrointestinal tract are seen exclusively during oral treatment. All sections from the lower esophagus to the colon may be affected. Ulcerations in the stomach, duodenum, and esophagus have been described. But abdominal 
pain, flatulence, and diarrhea are much more common [24, 25]. In the presence of intolerable symptoms, a switch should be made to an intravenous bisphosphonate.

\section{Renal Toxicity}

Almost no side effect has in the last few years led to such heated discussion as renal toxicity from bisphosphonates. To be sure, all bisphosphonates can damage the tubule system, but there are significant differences between the individual drugs. Following oral or parenteral administration, bisphosphonates are either stored in the bones (30-60\%) or remain unmetabolized and are excreted renally. Influx into the tubular cells is passive and depends only on serum concentration and protein binding. An active limited transportation mechanism forms the basis for excretion into the lumen. If this mechanism is overloaded, an accumulation of bisphosphonates in the tubular cells with induction of apoptotic processes can occur [26,27]. There is no evidence of renal complications with oral bisphosphonates at therapeutic doses. The following is recommended to avoid kidney damage: strict adherence to the recommended measures on the package insert; maintenance of good hydration; dose reduction if there is an increase in creatinine (i.e. restriction on calculated clearance).

\section{Osteonecrosis of the Jaw}

Osteonecrosis of the mandible and the maxilla (osteonecrosis of the jaw, ONJ) while being treated with bisphosphonates was first described in 2003, although reference is made in publications retrospective to earlier manifestations [28, 29]. In Germany, since the creation of a central registry for ONJ at the Charité Hospital in Berlin, more than 1,000 cases have been registered (mid-2010), and every week there are 3-5 new entries ( $w w w$. charite.de/zmk). Among the 932 evaluated cases with malignancies, $37 \%$ had breast cancer, $14 \%$ prostate cancer, $12 \%$ multiple myeloma, and $37 \%$ are divided among other tumor entities. Most osteonecroses $(85 \%)$ appeared in the first 4 years of treatment. More than $68 \%$ of the registered patients were treated with zolondrate, $17 \%$ with pamidronate, and $8.5 \%$ with ibandronate, most others with a sequence of the named bisphosphonates. Cases while on oral therapy are rare, and ONJ while on clodronate is unknown [30].

First data related to the incidence of ONJ have become available from prospective studies comparing zoledronic acid and the RANKL antibody denosumab for metastatic bone disease. The results show a comparable frequency for both drugs between 1 and $2 \%$ within the first 2 years of treatment $[31,32]$. One of the current hypotheses on the development of this complication assumes that ONJ represents the final stage of an osteomyelitis that has occurred previously. Macrophages and osteoclasts originate from the same stem cell line and are inhibited by bisphosphonates so that defense mechanisms are suppressed and existing infections are able to spread. Whether the anti-angiogenetic effect of biosphosphonates is pathophysiologically relevant is still unclear.
A dental procedure precedes most ONJs. And although this is not proven by studies (evidence-based), in the case of manipulation of the teeth or jawbone associated with an increased rate of turnover, bisphosphonate treatment should be interrupted for 1 month before and 1 month after the operation. In any case, all manipulations should be carried out with antibiotic protection. Because treatment of ONJ is unusually complicated, prophylactic teeth cleaning and treatment of all potential foci of inflammation should be performed before starting long-term treatment. If in doubt, an inspection of the oral cavity within the context of tumor follow-up is appropriate.

\section{Recommendations for the Use of Bisphosphonates in Metastatic Breast Cancer}

When acute complications occur, such as acute severe bone pain and hypercalcemia, intravenous bisphosphonates should be used. They show faster and better effectiveness than oral bisphosphonates.

A long-lasting oral therapy also can be used for asymptomatic and oligosymptomatic bone metastases besides the interval therapy.

Even if there is no scientific evidence, bisphosphonate treatment should be started immediately after diagnosis of metastatic bone disease and continued lifelong. Resistance against bisphosphonates is not known.

For treatment of tumor therapy-induced osteoporosis (particularly upon androgen and estrogen withdrawal), all bisphosphonates can be used (but only etidronate, alendronate, risedronate, ibandronate and zoledronate have been approved for treatment of osteoporosis), at which the dosage of the two last-named bisphosphonates is substantially lower than in oncology.

To avoid renal complications, it is recommended (especially for pamidronate and zoledronate) to measure serum creatinine and to calculate creatinine clearance (CockroftGault formula).

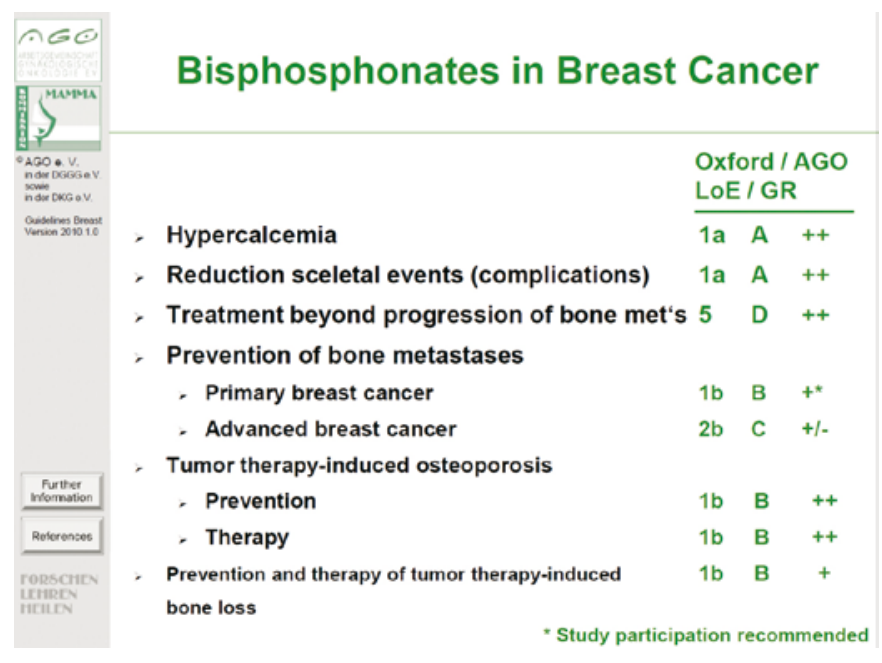

Fig. 7. AGO guidelines for the use of bisphosphonates in breast cancer. 
To reduce ONJ, it is recommended to bring the patient to do dental examinations and treatments before the use of bisphosphonates. For patients that require dental procedures during bisphosphonate treatment, a 2-month interruption of infusions is recommended besides antibiotic prophylaxis (fig. 7).

Recommended dosages of bisphosphonates are listed in table 1.
Table 1. Recommended dosages of bisphosphonates

\begin{tabular}{lll}
\hline Name of BP & Dosage & Interval \\
\hline Clodronate i.v. & $1,500 \mathrm{mg}$ & 4 weeks \\
Clodronate oral & $1,600 / 1,040 \mathrm{mg}$ & daily \\
Pamidronate & $90 \mathrm{mg}$ & 4 weeks \\
Ibandronate i.v. & $6 \mathrm{mg}$ & $3-4$ weeks \\
Ibandronate oral & $50 \mathrm{mg}$ & daily \\
Zoledronate & $4 \mathrm{mg}$ & 4 weeks \\
\hline
\end{tabular}

$\mathrm{BP}=$ Bisphosphonate; i.v. $=$ intravenous.

\section{Conflict of Interest}

The author declares no conflict of interest. He has received speakers honoraria from and is advisor for Amgen, Novartis and Roche.

\section{References}

1 Mundy GR: Metastasis to bone: causes, consequences and therapeutic opportunities. Nature Rev 2002;2:584-593.

2 Diel IJ, Solomayer EF, Bastert G: Treatment of metastatic bone disease in breast cancer: bisphosphonates. Clin Breast Cancer 2000;1:43-51.

3 Rodan GA, Fleisch H: Bisphosphonates: mechanisms of action. J Clin Invest 1996;97:2692-2696.

$\checkmark 4$ Rogers MJ, Frith JC, Luckman SP, et al.: Molecular mechanism of action of bisphosphonates. Bone 1999;24:73S-79S.

$\checkmark 5$ Luckman SP, Hughes DE, Coxon FP, et al.: Nitrogen-containing bisphosphonates inhibit the mevalonate pathway and prevent post-translational prenylation of GTP-binding proteins, including RAS. J Bone Miner Res 1998;13:581-589.

6 Selander KS, Mönkkönen J, Karhukorpi EK, et al.: Characteristics of clodronate-induced apoptosis in osteoclasts and macrophages. Mol Pharmacol 1996;50:1127-1138.

7 Paterson AHG, Powles TJ, Kanis JA, et al.: Double-blind controlled trial of oral clodronate in patients with bone metastases from breast cancer. J Clin Oncol 1993;11:59-65.

8 Hortobagyi GN, Theriault RL, Porter L, et al.: Efficacy of pamidronate in reducing skeletal complications in patients with breast cancer and lytic bone metastases. N Engl J Med 1996;335:17851791.

9 Hortobagyi GN, Theriault RL, Lipton A, et al.: Long-term prevention of skeletal complications of metastatic breast cancer with pamidronate. J Clin Oncol 1998;16:2038-2044.

10 Theriault RL, Lipton A, Hortobagyi GN, et al.: Pamidronate reduces skeletal morbidity in woman with advanced breast cancer and lytic bone lesions: a randomized, placebo-controlled trial. J Clin Oncol 1999;17:846-854.

11 Lipton A, Theriault RL, Hortobagyi GN: Pamidronate prevents skeletal complications and is effective palliative treatment in woman with breast carcinoma and osteolytic bone metastases: longterm follow-up of two randomized, placebo-controlled trials. Cancer 2000;34:2021-2026.

12 Ralston SH, Thiébaud D, Herrmann Z, et al.: Dose-response study of ibandronate in the treatment of cancer-associated hypercalcaemia. Br J Cancer 1997;75:295-300.
13 Body JJ, Diel IJ, Lichinitser MR, et al.: Intravenous ibandronate reduces the incidence of skeletal complications in patients with breast cancer and bone metastases. Ann Oncol 2003;14:1399-1405.

14 Diel IJ, Body JJ, Lichinitser MR, et al.: Improved quality of life for long-term treatment with the bisphosphonate ibandronate in patients with metastatic bone disease due to breast cancer. Eur J Cancer 2004;40:1704-1712.

15 Body JJ, Diel IJ, Lichinitser M, et al.: Oral ibandronate reduces the risk of skeletal complications in breast cancer patients with metastatic bone disease; results from two randomized, placebo-controlled phase III studies. Br J Cancer 2004;90:11331137.

16 Tripathy D, Lichinitser M, Lazarev A. et al.: Oral ibandronate for the treatment of metastatic bone disease in breast cancer: efficacy and safety results from a randomized, double-blind, placebo-controlled trial. Ann Oncol 2004;15:743-750.

17 Body JJ, Diel IJ, Bell R, et al.: Oral ibandronate improves bone pain and preserves quality of life in patients with skeletal metastases due to breast cancer. Pain 2004;111:306-312.

18 Major P, Lortholary A, Hon J, et al.: Zoledronic acid is superior to pamidronate in the treatment of hypercalcemia of malignancy: a pooled analysis of two randomized, controlled clinical trials. J Clin Oncol 2001;19:558-567.

19 Rosen LS, Gordon D, Kaminski M, et al.: Zoledronic acid versus pamidronate in the treatment of skeletal metastases in patients with breast cancer or osteolytic lesions of multiple myeloma: a phase III, double-blind comparative trial. Cancer J 2001;7:377-387.

20 Rosen LS, Gordon D, Kaminski M, et al.: Longterm efficacy and safety of zoledronic acid compared with pamidonate disodium in the treatment of skeletal complications in patients with advanced multiple myeloma or breast cancer. Cancer 2003;98:1735-1744.

21 Rosen LS, Gordon DH, Dugan W, et al.: Zoledronic acid is superior to pamidronate for the treatment of bone metastases in breast carcinoma patients with at least one osteolytic lesion. Cancer 2004;100:36-43.
22 Kohno N, Aogi K, Minami H, et al.: Zoledronic acid significantly reduces skeletal complications compared with placebo in Japanese women with bone metastases from breast cancer: a randomized, placebo-controlled trial. J Clin Oncol 2005;23:3314-3321.

23 Thiebaud D, Sauty A, Burckhardt P, et al.: An in vitro and in vivo study of cytokines in the acutephase response associated with bisphosphonates. Calcif Tissue Int 1997:61:386-392.

24 De Groen PC, Lubbe DF, Hirsch LJ, et al.: Esophagitis associated with the use of alendronate. New Engl J Med 1996;335:1016-1021.

25 Marshall JK: The gastrointestinal tolerability and safety of oral bisphosphonates. Expert Opin Drug Saf 2002;1:71-78.

26 Markowitz GS, Appel GB, Fine PL, et al.: Collapsing focal segmental glomerulosclerosis following treatment with high-dose pamidronate. J Am Soc Nephrol 2001;12:1164-1172.

27 Markowitz GS, Fine PL, Stack JI, et al.: Toxic acute tubular necrosis following treatment with zoledronate (Zometa). Kidney Int 2003;64:281289.

28 Marx RE: Pamidronate (Aredia) and zoledronate (Zometa) induced avascular necrosis of the jaws: a growing epidemic. J Oral Maxillofac Surg 2003;61:1115-1117.

29 Ruggiero SL, Mehrota B, Rosenberg TJ, Engroff SL: Osteonecrosis of the jaws associated with the use of bisphosphonates: a review of 63 cases. J Oral Maxillofac Surg 2004;62:527-534.

30 Diel IJ, Fogelman I, Hoffmeister B, et al.: Pathophysiology, risk factors and management of bisphosphonate-associated osteonecrosis of the jaw: is there a diverse relationship of amino- and non-amino-bisphosphonates? Crit Rev Oncol 2007;64:198-207.

31 Stopeck A, de Boer R, Fujiwara Y, et al.: A comparison of denusomab versus zoledronic acid for the prevention of skeletal-related events in breast cancer patients with bone metastases. Cancer Res 2009;69:suppl 24, abstr 22.

32 Henry D, von Moos R, Vadhan-Raj S, et al.: A double-blind, randomized study of denosumab versus zoledronic acid for the treatment of bone metastases in patients with advanced cancer (excluding breast and prostate cancer) or multiple myeloma. Eur J Cancer 2009;suppl 7:20LBA. 